NASA/TM—2008-215196

\title{
GRC Supporting Technology for NASA's Advanced Stirling Radioisotope Generator (ASRG)
}

Jeffrey G. Schreiber and Lanny G. Thieme

Glenn Research Center, Cleveland, Ohio 


\section{NASA STI Program . . . in Profile}

Since its founding, NASA has been dedicated to the advancement of aeronautics and space science. The NASA Scientific and Technical Information (STI) program plays a key part in helping NASA maintain this important role.

The NASA STI Program operates under the auspices of the Agency Chief Information Officer. It collects, organizes, provides for archiving, and disseminates NASA's STI. The NASA STI program provides access to the NASA Aeronautics and Space Database and its public interface, the NASA Technical Reports Server, thus providing one of the largest collections of aeronautical and space science STI in the world. Results are published in both non-NASA channels and by NASA in the NASA STI Report Series, which includes the following report types:

- TECHNICAL PUBLICATION. Reports of completed research or a major significant phase of research that present the results of NASA programs and include extensive data or theoretical analysis. Includes compilations of significant scientific and technical data and information deemed to be of continuing reference value. NASA counterpart of peer-reviewed formal professional papers but has less stringent limitations on manuscript length and extent of graphic presentations.

- TECHNICAL MEMORANDUM. Scientific and technical findings that are preliminary or of specialized interest, e.g., quick release reports, working papers, and bibliographies that contain minimal annotation. Does not contain extensive analysis.

- CONTRACTOR REPORT. Scientific and technical findings by NASA-sponsored contractors and grantees.

- CONFERENCE PUBLICATION. Collected papers from scientific and technical conferences, symposia, seminars, or other meetings sponsored or cosponsored by NASA.

- SPECIAL PUBLICATION. Scientific, technical, or historical information from NASA programs, projects, and missions, often concerned with subjects having substantial public interest.

- TECHNICAL TRANSLATION. Englishlanguage translations of foreign scientific and technical material pertinent to NASA's mission.

Specialized services also include creating custom thesauri, building customized databases, organizing and publishing research results.

For more information about the NASA STI program, see the following:

- Access the NASA STI program home page at http://www.sti.nasa.gov

- E-mail your question via the Internet to help@ sti.nasa.gov

- Fax your question to the NASA STI Help Desk at 301-621-0134

- Telephone the NASA STI Help Desk at 301-621-0390

- Write to: NASA Center for AeroSpace Information (CASI) 7115 Standard Drive Hanover, MD 21076-1320 
NASA/TM-2008-215196

\section{GRC Supporting Technology for NASA's Advanced Stirling Radioisotope Generator (ASRG)}

Jeffrey G. Schreiber and Lanny G. Thieme

Glenn Research Center, Cleveland, Ohio

Prepared for the

Space Technology and Applications International Forum (STAIF-2008)

sponsored by the Institute for Space and Nuclear Power Studies at the University of New Mexico Albuquerque, New Mexico, February 10-14, 2008

National Aeronautics and

Space Administration

Glenn Research Center

Cleveland, Ohio 44135 


\section{Acknowledgments}

The work described in this paper was performed for the Science Mission Directorate (SMD) and the Radioisotope Power System (RPS) Program, which provided funding for these projects.

This report is a formal draft or working paper, intended to solicit comments and ideas from a technical peer group. subject to revision as analysis proceeds.

Trade names and trademarks are used in this report for identification only. Their usage does not constitute an official endorsement, either expressed or implied, by the National Aeronautics and Space Administration.

Level of Review: This material has been technically reviewed by technical management.

Available from

NASA Center for Aerospace Information 7115 Standard Drive

Hanover, MD 21076-1320
National Technical Information Service 5285 Port Royal Road Springfield, VA 22161 


\title{
GRC Supporting Technology for NASA's Advanced Stirling Radioisotope Generator (ASRG)
}

\author{
Jeffrey G. Schreiber and Lanny G. Thieme \\ National Aeronautics and Space Administration \\ Glenn Research Center \\ Cleveland, Ohio 44135
}

\begin{abstract}
From 1999 to 2006, the NASA Glenn Research Center (GRC) supported a NASA project to develop a high-efficiency, nominal 110-We Stirling Radioisotope Generator (SRG110) for potential use on NASA missions. Lockheed Martin was selected as the System Integration Contractor for the SRG110, under contract to the Department of Energy (DOE). The potential applications included deep space missions, and Mars rovers. The project was redirected in 2006 to make use of the Advanced Stirling Convertor (ASC) that was being developed by Sunpower, Inc. under contract to GRC, which would reduce the mass of the generator and increase the power output. This change would approximately double the specific power and result in the Advanced Stirling Radioisotope Generator (ASRG). The SRG110 supporting technology effort at GRC was replanned to support the integration of the Sunpower convertor and the ASRG. This paper describes the ASRG supporting technology effort at GRC and provides details of the contributions in some of the key areas. The GRC tasks include convertor extended-operation testing in air and in thermal vacuum environments, heater head life assessment, materials studies, permanent magnet characterization and aging tests, structural dynamics testing, electromagnetic interference and electromagnetic compatibility characterization, evaluation of organic materials, reliability studies, and analysis to support controller development.
\end{abstract}

\section{Introduction}

The NASA Glenn Research Center (GRC) supported the development of a high-efficiency, nominal 110-We Stirling Radioisotope Generator (SRG110) from 1999 until the project was redirected in 2006 (Schreiber, 2006). The SRG110 was intended for use on potential NASA Space Science missions. Lockheed Martin (LM) was selected to be the System Integration Contractor for the SRG110 (Cockfield, 2002), under contract to the Department of Energy (DOE). Infinia Corporation (formerly Stirling Technology Company) developed the Stirling convertor, initially under contract to DOE and then as a subcontractor to LM. The SRG110 Qualification Unit (QU) was projected to have a specific power of $3.45 \mathrm{We} / \mathrm{kg}$, with the generator meeting the original targets of greater than $110 \mathrm{We}$ output power and a mass of approximately $32 \mathrm{~kg}$. While the generator did provide a significant increase in efficiency and thereby a reduction in plutonium inventory required compared to alternative radioisotope generators, it was felt that a Stirling generator would also need to improve the specific power for it to become widely accepted for space power applications. The development was redirected by NASA HQ in March 2006, to use the Advanced Stirling Convertor (ASC) that was being developed by Sunpower, Inc. under a NASA Research Announcement (NRA) contract with GRC (Wong, 2006). This change has resulted in the Advanced Stirling Radioisotope Generator (ASRG) that is projected to have a specific power of $7.0 \mathrm{We} / \mathrm{kg}$ for the QU (Chan, 2007). The greater than twofold increase in specific power of the generator has been accomplished with as much heritage as possible being used in design and hardware from the SRG110 generator; therefore, the ASRG generator does not represent a system-level optimized design. However, it is worth noting that the SRG110 generator and the Stirling convertors from Infinia were achieving their programmatic goals and were on track to providing a long life, high efficiency flight generator.

GRC had established a supporting technology effort for the SRG110 project to reduce risk as the Stirling Technology Demonstration Convertor (TDC) was transitioning from technology development 
toward flight development. In response to the redirection of the generator development effort, the GRC supporting technology effort was replanned in response to the technologies that are used in the ASC and how it operates within the ASRG system. This paper provides an overview of the GRC supporting technology effort for the ASRG project. The GRC tasks include reliability analyses, extended operation testing of convertors in air and in thermal vacuum environment, materials work in metallics and organics, structures, analysis of controllers, electromagnetic interference and electromagnetic compatibility (EMI/EMC), advanced analysis including computational fluid dynamics (CFD), permanent magnet characterization, and structural dynamics. All of the tasks are intended to mitigate risk as the technology progresses towards a potential flight application, and not to enhance performance. Accomplishments from some of the areas will be highlighted.

\section{The Advanced Stirling Radioisotope Generator (ASRG)}

The ASRG Engineering Unit (EU) generator is shown in figure 1. The purpose of the EU is to validate the engineering of the generator and it therefore uses electrically heated simulators of the General Purpose Heat Source (GPHS) modules. Two GPHS simulators are used; one for each of the two ASC convertors. The generator is based on a configuration of dual-opposed convertors for dynamically balanced operation. The generator shown has end enclosures with feed throughs for the electric heaters and instrumentation that will be used on the EU. The QU and flight units will have a simplified end enclosure. The ASRG EU uses one of the existing beryllium housings from the SRG110 for the outboard housing of the generator, and a shorter housing being fabricated for the inboard end. The shorter housing was required as the ASC's are approximately $200 \mathrm{~mm}$ (8 in.) in length compared to $330 \mathrm{~mm}$ (13 in.) for the SRG110 convertors. The overall dimensions for the ASRG EU are $724 \mathrm{~mm}$ long (28.5 in.), $457 \mathrm{~mm}$ high (18 in.), and $292 \mathrm{~mm}$ wide (11.5 in.). Vacuum foil insulation provides superior performance for deep space missions; however, Microtherm HT (Microtherm, Inc.) bulk insulation was selected to satisfy the requirement for multi-mission application, in the vacuum of space or in an atmosphere as exists on Mars. The Jet Propulsion Laboratory (JPL) is investigating aerogel to further enhance the specific power of the generator. Aerogel has flight heritage on Sojourner, Mars Exploration Rovers, and Stardust for comet sample collection. Aerogel is slightly more than half of the density of Microtherm HT, which would result in further mass saving.

Waste heat from each ASC convertor is conducted through a cold side adapter flange (CSAF) to the beryllium housing. Beryllium fins are attached to the corners of the housing to provide extended surface



Figure 1.-ASRG engineering unit with two ASC-E convertors and showing many of the key components. 
to reduce the temperature at which the waste heat is rejected and thus improve cycle efficiency. The $66 \mathrm{~mm}$ (2.6 in.) length of the fin remains from the SRG110 design and may be optimized in the future. The fins are bolted to the corners of the housing where a cooling loop may also be attached if desired by the mission.

\section{The Advanced Stirling Convertor}

The ASC was developed by Sunpower, Inc. under an NRA contract managed by GRC (Wong et al., 2006). Development of the ASC was planned to be a three-phase effort, resulting in the Frequency Test Bed, the ASC-1, and the ASC-2 in each successive phase. The specifications for the ASC development effort called for high efficiency and low mass, with long life consistent with a mission of up to $14 \mathrm{yr}$. At the time that the generator development was redirected, the ASC NRA effort was in the second of the three phases, and therefore the ASRG would make use of a derivative of ASC-1, which would become known as the ASC-E (Shaltens, Wong, 2007). The designation of E was based on the intended use in the generator EU (Wood et al., 2006). The NRA design was based on the use of MarM-247 for the heater head material which allows operation up to $850^{\circ} \mathrm{C}$ hot-end temperature. With this hot-end temperature and a temperature ratio of 3.1, the efficiency of the convertor can reach nearly 40 percent from heat input to alternating current output from the alternator. Due to the ongoing development of the MarM-247 heater head and the time required for fabricating heater heads from that material, it was decided that the ASRG EU would use ASC's fabricated with Inconel 718 (IN718) heater heads, thereby limiting the hot-end temperature to about $650{ }^{\circ} \mathrm{C}$.

The purpose of the NRA project was to develop the power conversion technology, and did not consider integration into a generator. The ASC-E's required thermal, electrical, and structural interfaces with the generator for successful system integration. A nickel heat collector was designed for the heater head, and a copper-alloy flange was designed for heat rejection. Both were similar to the configurations used in the SRG110 integration. Flight quality electrical feed throughs for power output from the linear alternator were integrated into the convertor design, and a flange was added to the aft end of the pressure vessel as a structural interface for the interconnect tube. The convertors developed under the NRA effort had externally mounted sensors for piston position, so an internal version of the Fast Linear Displacement Transducer (FLDT) was developed.

Three ASC-E convertors were fabricated by Sunpower and GRC and delivered in October 2007 to the $\mathrm{DOE} / \mathrm{LM}$ team for integration into the generator. Two of the convertors will be used in the EU generator, and one will remain as a spare. The convertors were designed, fabricated, assembled, and tested to specification in less than 20 months after redirection. Two of the convertors are shown in figure 2 following testing. They are hermetically sealed units, with all interfaces prepared for integration into the generator. All three convertors exceeded the performance specifications, following a workmanship vibration test at GRC.

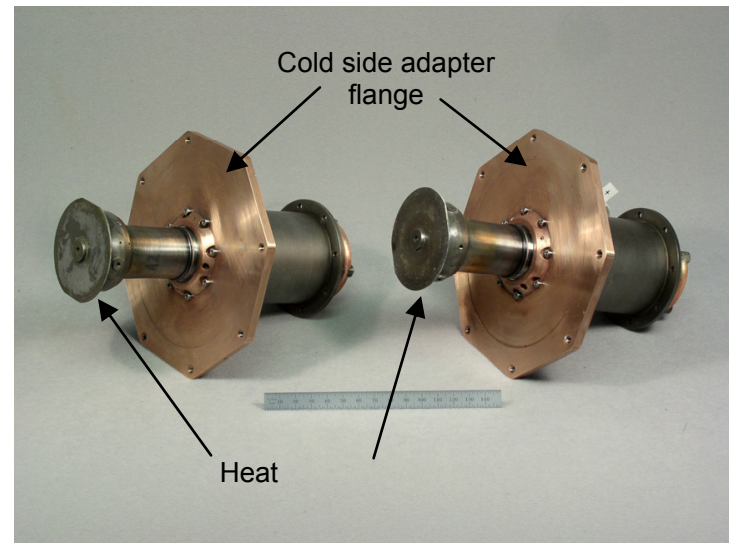

Figure 2.-Two of the ASC-E convertors ready for integration into the ASRG-EU generator. 


\section{GRC Supporting Technology Development for the ASRG}

The GRC supporting technology effort that addressed issues for the SRG110 has been widely reported (Schreiber, 2006; Schreiber and Thieme, 2007). The primary purpose of the effort was to reduce risk and enhance reliability wherever possible for the long-life generator. With the programmatic redirection for the generator to use the ASC convertors, the GRC technology effort was replanned. Some of the technical issues to be addressed for the ASC-E's remained the same as for the Technology Demonstration Convertors (TDC's), however, others were different. The GRC technology efforts focus on issues related to the Stirling convertor and not the generator; however, by the nature of the integrated system, these technology issues inherently overlap. Since the technology effort supports flight development, all of the tasks ultimately contributed to life and reliability, and do not pursue reduction in mass or increases in efficiency.

The various tasks that are underway at GRC are outlined below. One additional task has been undertaken by JPL, where aerogel compositions are being formulated to try to achieve a comparable thermal property to that of Microtherm HT with greatly reduced mass. The insulation in the ASRG is used not only to reduce heat loss during normal operation, but also to dump heat when the GPHS modules are nearing their upper temperature limits. This is done by the insulation shrinking as the temperature rises and heat is then radiated from the GPHS module to the beryllium housing. Aerogel shrinkage testing at elevated temperature has been performed by JPL to demonstrate the emergency heat dump capability required for the ASRG. To date, the Aerogel insulation has demonstrated the mass reduction that was anticipated, and now the formulation is being tailored to reduce the thermal conductivity. At the current state of development, the Aerogel insulation has not resulted in the significant increase in generator specific power that was being sought.

\section{Extended-Operation of Stirling Convertors}

Operation of prototypical free-piston Stirling convertors for radioisotope generators began at the GRC Stirling Research Laboratory (SRL) in 1999 with the arrival of a pair of TDC's, and now continues with operation of ASC's. The total operating time at GRC has surpassed 146,000 hr on 14 convertors. Six other convertors have been operated for short-term, focused tests. Many tests were performed initially to investigate issues such as transient response, dynamic balance, operation of a thermally-imbalanced pair of convertors, advanced controllers, and stability tests. However, due to the long-life requirement of the application, operation of convertors at GRC has centered on extended operation to investigate any aging effects that may exist. Over the past year, the lab has transitioned to operation of ASC's and other convertors containing the same technologies. Throughout these tests, there has not been any evidence of degradation in convertor performance, other than what can be attributed to the facility or the operator.

\section{Extended Operation of ASC Convertors}

As mentioned previously, the NRA contract was planned to have three phases, resulting in the development of the FTB's in Phase I, the ASC-1's in Phase II, and the ASC-2's in Phase III. The FTB's were used to demonstrate operation at frequencies over $100 \mathrm{~Hz}$, the ASC-1's demonstrated operation at hot-end temperatures up to $850^{\circ} \mathrm{C}$ based on the use of a MarM-247 heater head, and Phase III will demonstrate a hermetically sealed convertor with a MarM-247 heater head. Fabrication of additional convertors ordered by GRC was underway as details of the ASC-E design were being completed that addressed system integration issues. The additional convertors were based on the most current designs that existed prior to the ASC-E, and were ordered to exercise the Quality Assurance (QA) system that was being established at Sunpower. Since the MarM-247 heater head was still under development, it was decided that the ASC-E's and the additional precursor convertors would use IN 718 for the heater head. The precursor convertors were designated ASC-0's, indicating the use of a less advanced heater head technology than would ultimately come out of the NRA development effort. 


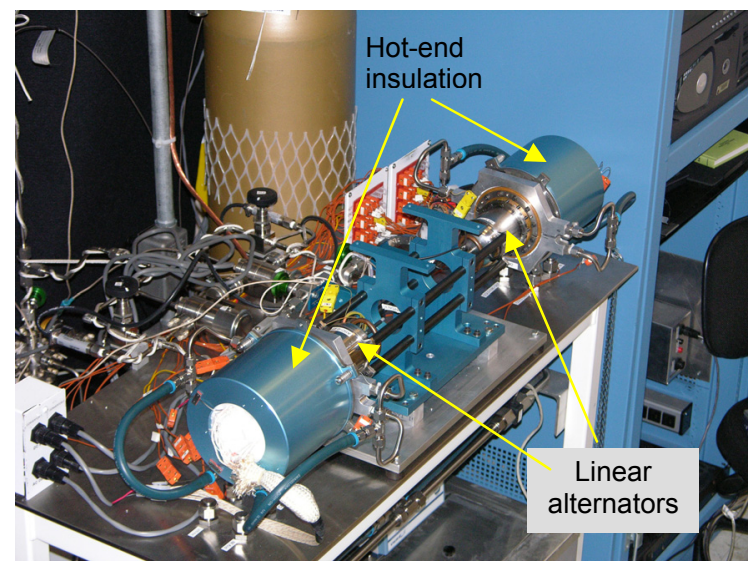

Figure 3.-One of the ASC-0's showing the nickel heat collector, the copper heat rejection flange, and the aluminum cooling collars.

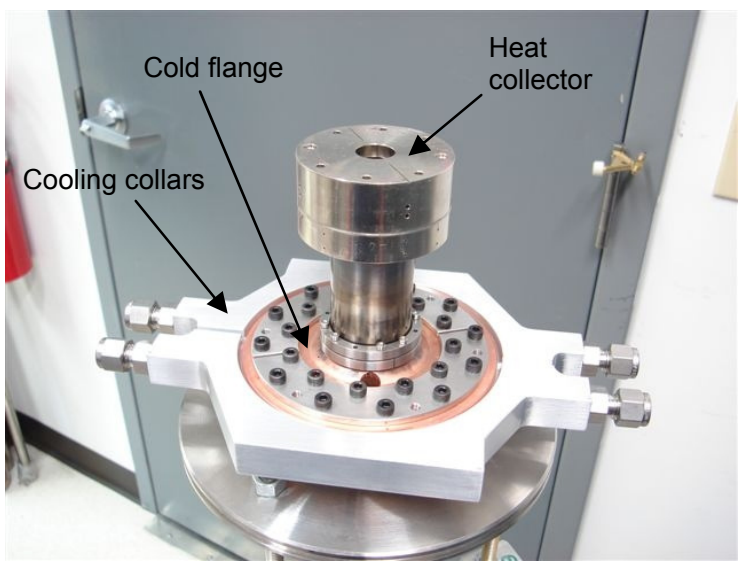

Figure 4.-ASC-0's operating on the test stand in the GRC Stirling lab.

The ASC- 0 design was based on the ASC-1 of the NRA project, but included an IN718 heater head and thermal interfaces for heat input and waste heat rejection. As shown in figure 3, a nickel heat collector was incorporated on each heater head that could interface with an electric resistance heater for operation in air, or a Borelectric (GE Advanced Ceramics) heater for operation in thermal vacuum. A copper flange was incorporated to conduct waste heat from the convertor to a heat rejection system. For operation in air, a nickel heating block is bolted to the nickel heat collector, and aluminum collars with coolant flow passages are attached to the copper flange as shown in figure 3. For testing in a thermal vacuum environment, a Borelectric heater is fastened to the heat collector and radiator panels are attached to the copper heat rejection flange.

The ASC-0's are hermetically sealed convertors, with the exception of the fill tube. It was decided that the fill tubes would have VCR (Swagelock Company) face seal fittings so that the convertors could interface with a gas management system that included a Residual Gas Analyzer (RGA). This feature allows the helium working fluid to be sampled during extended operation to look for signs of aging of the organics used in assembly of the convertor. The system takes a sufficiently small amount of helium that the loss of convertor charge pressure is not detected by the data system. This configuration maintains the option of sealing the fill tube at some later time to have a fully hermetic convertor. Gas analysis has not shown an indication of decomposition; however, it has proven itself useful in developing techniques for achieving very clean bake out of the convertors and subsequent back fill with high purity helium. A total of four ASC-0's were fabricated and delivered to GRC, the first pair beginning operation at GRC in February 2007 and the second pair beginning in May of 2007.

ASC-0's nos. 1 and 2 were operated in air for approximately $600 \mathrm{hr}$, as the performance was characterized. A pair of ASC-0's installed on a test stand is shown in figure 4. They were then fitted with the heater and cooling hardware needed for operation in a thermal vacuum environment, and installed into Vacuum Facility 67 (VF-67) at GRC. Figure 5 shows the test article including the controller, the radiator panels, and the insulation that covers the heated section. The heating system simulates the heat generated by a GPHS module, and the radiator panels are cooled by radiation heat transfer to the cold walls of the vacuum facility. As of October 2007, the convertors have operated for over 4,600 hr in thermal vacuum, for a total operating time at GRC of greater than 5,200 hr. Performance over this time has remained unchanged. The test article will remain in extended operation in the vacuum facility until the facility is needed for testing of other hardware. When the convertors are removed from the vacuum facility, they will be returned to extended operation in air. The second pair of ASC-0's, designated as nos. 3 and 4, has been placed in extended operation in air. The convertors have accumulated approximately $800 \mathrm{hr}$ and are 


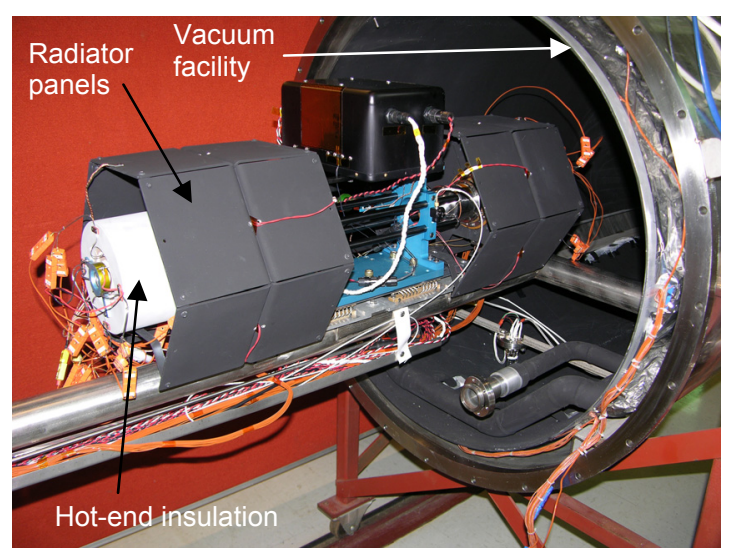

Figure 5.-ASC-0's nos. 1 and 2 in thermal vacuum test configuration.

continuing operation. Similar to the first pair of ASC-0's, the performance has remained unchanged throughout the test.

Sunpower produced four ASC-1's during the second phase of the NRA technology development effort. Development of the ASC-1's was intended to investigate the manufacturing issues related to use of a MarM-247 heater head and to demonstrate operation at temperatures up to $850^{\circ} \mathrm{C}$. Accomplishing these goals did not require the convertors to be hermetically sealed, and they are therefore sealed with o-rings. ASC-1 nos. 3 and 4 were installed in the SRL at GRC for extended operation, with initial operation beginning in May 2007. These convertors were based on the same mechanical design as the ASC-E's and make use of the same system of gas bearings for non-contacting operation. The heaters are commercially available electric resistance heaters that use nickel-chromium resistance wire. For operation of the heater head at $850^{\circ} \mathrm{C}$, it has been estimated, and data has confirmed, that the heating elements would operate between 900 and $1,000^{\circ} \mathrm{C}$. To extend the life of the electric resistance heaters, a mounting system was fabricated that includes the capability to control the atmosphere around the heating elements. This will be used to maintain an inert gas atmosphere of argon when the heater head is operated above $650{ }^{\circ} \mathrm{C}$. Cans similar to those shown for the ASC-0's operating in air support the thermal insulation for the hot end of the convertor and are also used to contain the argon cover gas to protect the heaters. The ASC-1's have operated for over $1,200 \mathrm{hr}$ since delivery to GRC.

A pair of convertors similar to the ASC-1's has been fabricated by Sunpower, but with the assembly being hermetically sealed with the exception of the fill port. These have been designated as ASC-1HS nos. 1 and 2. Extended operation of the ASC-1HS pair should begin at GRC late in 2007. Following characterization in air, these convertors will be moved into thermal vacuum operation as convertors ASC-0 nos. 1 and 2 return to in-air operation.

Throughout these extended operation tests, data will be taken are regular intervals and studied to investigate any potential aging effects. Similar to gas analysis of the working fluid, other parameters will be monitored to check for any changes. Accelerometers are mounted on each test article and the acceleration data are checked in magnitude and in frequency content. A system of acoustic measurements is being investigated that will be used to characterize the acoustic signature with contact of the moving components and compare this to the signature when the gas bearing system is functioning properly. These data will be used to check for no change over time, and to verify that the convertors are operating at all times with non-contacting operation.

\section{Extended Operation of TDC's}

Extended operation of TDC's nos. 13 through 16 continues. This was previously described in Schreiber and Thieme (2007). While these convertors are somewhat different in configuration from those 
being integrated into the ASRG, they do contain some of the same features as used in the ASC-E's. Specifically, the magnets are very similar, and some of the organics, including thread locker, adhesives, and surface treatments, are similar or identical to those used in the ASC-E's. Continuous operation of these convertors has been maintained, and gas sample analyses continue. TDC's nos. 13 and 14 surpassed $32,000 \mathrm{hr}$ in September 2007, with only facility issues causing any down time. These convertors continue to show no signs of performance degradation other than what can be most likely attributed to oxidation of the regenerators early in the test program, which was found to be due to permeation of atmospheric air into the convertors through the o-rings. The gas sample analyses also are showing no indication of decomposition of the organics or any other chemical processes. TDC's nos. 15 and 16 surpassed $18,000 \mathrm{hr}$ of operation in September 2007 and similarly had no down time other than that due to facility issues. No failures or otherwise anomalous operation has been found that could be attributed to the TDC's, and extended operation is continuing as part of the ASRG effort.

TDC's nos. 5 and 6 had been operated previously in the VF-67 that ASC-0 nos. 1 and 2 now occupy (Oriti, 2006). After completing the 10,000-hour test, the TDC's were removed from the vacuum facility to begin preparation for the upcoming test of ASC's. After numerous facility issues and support equipment issues were resolved, the TDC's operated reliably in the vacuum facility. As of October 2007, over $126,000 \mathrm{hr}$ of operation has been accumulated on TDC's at GRC with no failures or change in performance, other than that attributed to operator error.

\section{Heater Head Life Assessment}

Heater head life is a critical element for achieving the 17-yr life of the convertor. The heater head is a thin-walled pressure vessel fabricated from IN718 for the ASC-E convertors and operating at a hot-end temperature of $640{ }^{\circ} \mathrm{C}$. The heater heads of the ASC-E2 convertors, to be used in the second-generation ASRG, will be made from MarM-247. This material was selected based on a GRC-screening study of a wide range of superalloys; this work is described by Bowman, Ritzert, and Freedman (2003). The hot-end operating temperature for the ASC-E2's has not yet been determined but could be as high as $850{ }^{\circ} \mathrm{C}$. The MarM-247 material is expected to significantly increase the operating margins on the heater head, compared to IN718, which was being operated very near its maximum use temperature in the ASC-E's.

GRC materials and structures personnel have developed an approach to characterize the long-term durability of the heater head. This involves both deterministic and probabilistic methods, material creep data based on GRC uniaxial creep testing, an extensive long-term creep and creep-rupture database (up to $87,000 \mathrm{hr}$ ) for IN718 using data from the Oak Ridge National Laboratories (ORNL), and heater head structural benchmark tests to factor in the true biaxial stress state and validate the analytical models. Uncertainties and variations in the material properties, the heater head geometry, and the convertor operating conditions are considered in the probabilistic analysis.

A linear elastic finite element analysis was completed for the ASC-E heater head geometry, and a preliminary probabilistic life assessment was performed. For different hot-end temperatures, allowable stresses were determined that achieve greater than 17 -yr life with 0.999 probability-of-survival. The overall result was that the ASC-E heater head dome and tapered-wall thicknesses were increased to meet the required life at $640{ }^{\circ} \mathrm{C}$. Efforts are now fully focused on the MarM-247 material.

Uniaxial creep testing is being completed on fine-grain (Microcast), medium-grain (conventional casting), and large-grain MarM-247. The large-grain test samples were provided by Pratt \& Whitney Rocketdyne (PWR). Sample thicknesses vary from 0.25 to $1 \mathrm{~mm}$, and tests have been conducted at temperatures ranging from 750 to $927^{\circ} \mathrm{C}$ and over a stress range of 68 to $276 \mathrm{MPa}$ (10 to $40 \mathrm{ksi}$ ). Over $215,000 \mathrm{hr}$ of total creep testing have been completed, with a maximum of over $23,700 \mathrm{hr}$ on a single sample (ongoing test at $850^{\circ} \mathrm{C}$ and $138 \mathrm{MPa}(20 \mathrm{ksi})$ for a medium-grain sample). Recently, creep tests have begun on samples taken from Microcast near-net-shape castings. The final selection of grain size for the ASC-E2 heater head will be based on the creep test data, helium permeability testing, and machining trials. 


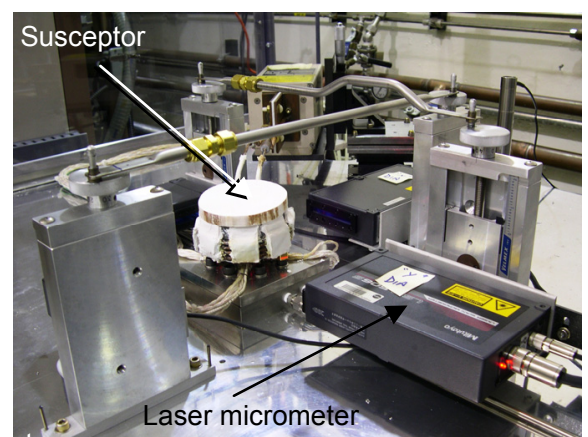

(a) Susceptor and laser micrometers.

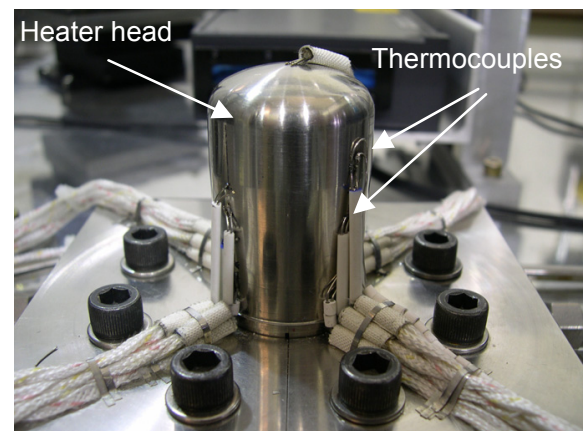

(b) Test heater head with thermocouples.

Figure 6.-Heater head structural benchmark test rig.

The first heater head structural benchmark test facility for testing ASC heater heads is nearing completion. The test setup is shown in figures 6 (a) and (b). Figure 6 (a) depicts the susceptor and laser micrometers for measuring diameter of the heater head. Figure 6 (b) shows a close-up view of the thermocoupled heater head. A second test facility is also being constructed. The first test article will be a large-grain MarM-247 heater head shell (pressure vessel only), that was originally built as a machining trial specimen. Once the final MarM-247 material has been selected and the heater head design approved for the ASC-E2, both a heater head shell and a full-up heater head will be fabricated for structural benchmark testing. The full-up heater head will include an external heat collector, which transfers heat from the heat source to the heater head, and an internal heat acceptor, which contains the Stirling heater helium passages.

Previous heater head creep testing performed at GRC for the SRG110 project relied on increased internal pressure to accelerate creep deformation. This experimental method produced data under just one stress-temperature condition for each generally lengthy test. GRC has now developed a "cascade" test procedure for ASC accelerated structural testing. Cascade testing, so-called for the cascade of experimental creep rates produced by a single test article over a wide range of stresses and at the temperature of interest, subjects a large volume of material to creep strain measurement. The method uses an inductively heated silicon carbide susceptor to generate uniform temperature over a major portion of the test article's tapered wall. In this way, internal pressure creates a multitude of biaxial stress ranges at the desired temperature: near the heat acceptor, the thicker wall results in a lower biaxial stress state, and, toward the cold rejector end, the thinner wall produces higher biaxial stresses. Two diametral extensometers, located $90^{\circ}$ apart, will measure real-time, gage-area strains at a critical hot-end location. In addition, two laser micrometers will be used to make periodic diameter measurements at discrete axial locations. Hot scans will record diameters at five axial locations approximately once a week. Roomtemperature scans will be made at about ten axial locations during planned and unplanned shutdowns, with these scans being made at least once a month. Heater head structural benchmark testing is described in more detail by Krause, Kalluri, and Bowman (2007).

Analysis has been completed of the GRC creep strain versus time data obtained from uniaxial creep testing of thick and thin specimens of the fine-grain Microcast MarM-247 material, which is the leading candidate for the ASC-E2 heater head. A creep model was developed that will first be used to perform deterministic, non-linear creep analysis of the heater head. This will be followed by a heater head probabilistic life analysis. Structural benchmark test results on the actual heater head and heater head shell will be factored into the life analysis, as data become available, to include the biaxial creep effects and validate the analysis. 


\section{Materials Studies}

Material studies are underway in multiple areas to ensure high reliability of the Stirling convertor. Some of these tasks are in their early stages, and few results are available; therefore, a brief outline of the activities will be presented. A few long-term creep samples remain under test from the SRG110 effort with much of the attention now being devoted to characterizing MarM-247. MarM-247 has been selected for future ASC builds primarily because it offers significant operating margin compared to IN718. MarM247 has a much higher temperature capability and is therefore not as sensitive to changes in the operating point. With the higher temperature capability, the operating temperature of future ASC's could be raised to approximately $850^{\circ} \mathrm{C}$, although there are diminishing returns at the generator level as hot-end temperatures are increased. Initial characterization has been based on uniaxial creep tests at three grain sizes. This test investigates the possibility of grain size influencing creep characteristics, as was found for IN718. As the data are accumulated, a selection will be made of the preferred grain that ensures long life with robust margin.

To further mitigate risk, a test rig has been designed and is being fabricated to characterize permeation of helium through a MarM-247 heater head. At the high hot end operating temperature, some relatively small amount of helium permeates through the heater head. For the IN718 heater head, it was determined by analysis that the loss of helium over a 14-year mission resulted in an immeasurable change in Stirling convertor performance. For the permeability testing, a MarM-247 heater head will be brazed to a stainless steel plug that will allow pressurization of the internal cavity of the head. The test fixture has been designed such that a vacuum can be pulled in the cavity around the outside of the heater head, and an RGA will be used to monitor the presence of helium in the surrounding cavity. The purpose of this test is to provide data to ensure reliability similar or better than that with the IN718.

As the hot-end temperature of the convertor is increased to take advantage of the capability of MarM-247, other features need to be studied to maintain reliability. Internal to the heater head, the heat acceptor and the displacer will operate at higher temperature, as will the heat collector on the outside. Higher-temperature, nickel-based superalloys are used for the displacer, and joining techniques must be evaluated to determine the life of braze joints. Typically, diffusion bonding is considered when temperatures are too high for long-life, high-reliability braze joints.

The ASC-E's with IN718 heater heads attach the heater head to the transition of the ASC-E by laser welding. This is not possible with a MarM-247 heater head, so another joining technique was needed. An inertia-welded joint was originally pursued under the ASC NRA effort, and proved to be successful. The MarM-247 head was inertia welded to an IN718 component, which could then be laser welded to the IN718 transition. An alternate method was developed at GRC that brazes a ring of IN625 to the heater head, which is then laser welded to the IN718 transition. Samples have been made and tested to verify sealing at proof pressure; however, full MarM-247 heater heads based on this fabrication technique remain to be tested in operating convertors.

Other activities in support of the ASC development include further refinement of regenerators made with oxidation-resistant materials and with techniques that eliminate shedding of fibers, evaluation of techniques for pinching and sealing the fill tube, exposure of Resistance Temperature Detectors to elevated temperatures to characterize potential aging effects, alternative materials that provide improved matching of thermal expansion coefficients of running components, and measurements of heater head grain texture.

\section{Evaluation of Convertor Organics}

Organic materials are used in limited amounts in the Stirling convertor, primarily in the linear alternator for such uses as electrical insulation, potting compounds, and structural bonding, and as a surface in close clearance seals where there might be temporary contact of moving parts. Organics characteristics being evaluated by the GRC Polymers branch include outgassing, magnet bond strength, thermal stability, long-term aging, and radiation tolerance. Resolutions of any organics materialprocessing issues that come up during convertor fabrication are also supported. 
Samples of each organic used in the ASC were received from Sunpower. The outgassing potential of each material was assessed using a methodology based on normalized weight loss measurements, as determined by thermogravimetric analysis (TGA). The typical bakeout used during ASC processing was completed for each sample. The outgassing characteristics for all the organics after bakeout were within the acceptable range. Short-term thermal stability tests were also completed. Most organics were thermally stable to $200{ }^{\circ} \mathrm{C}$ or higher, and the thermal stability of all organics exceeded the maximum operating temperature of $125^{\circ} \mathrm{C}$ with margin.

Cure kinetics testing was completed on Hysol EA9394 epoxy, used in the ASC for bonding magnets and lamination stacks and potting the linear alternator coil. A cure cycle was recommended based on the time-temperature-transformation diagram developed from the cure kinetics testing and outgassing characteristics. Mixing parameters were also optimized, based on the degree of epoxy cure, phase separation, and minimization of outgassing and trapped voids. Various parameters for both hand mixing and mixing with a Thinky mixer were evaluated, including mass of the epoxy resin, mixing time, ratio of revolution to rotation frequency for both Thinky mixing and defoaming, vacuum degassing time, and mixing sequence. An optimized sample achieved with the Thinky mixer is compared to hand-mixed samples in figure 7.

A long-term aging test was recently initiated for key ASC organic materials, including Hysol EA9394 and the FLDT potting epoxy. Test samples were randomly distributed into four sets for three aging times and a baseline control. The sorted samples were loaded into three pressure vessels, one each for fourmonth, one-year, and two-year aging. The pressure vessels were then installed in the aging test setup in a high-temperature oven. A vacuum was initially applied to the test samples in all three pressure vessels for an hour, and then they were heated to $115^{\circ} \mathrm{C}$ and baked/dried overnight under the vacuum. The final test conditions were then established by pressurizing the pressure vessels with ultra-pure (99.999 percent) helium to $515 \mathrm{psig}$ and heating to the aging temperature of $125^{\circ} \mathrm{C}$. Following completion of each aging period, test samples will be characterized and used for static bond strength, fatigue, and thermomechanical fatigue testing.

Nearly two years of aging were completed on 3M Scotch-Weld (3M Company) 2216 B/A Gray and Master Bond Supreme 10HT epoxies that were under consideration in the previous SRG110 project. Samples have been characterized for four-month and one-year aging, and characterization of the two-year samples is now underway. These two epoxies represent classes of epoxies with low- and high-glass transition temperatures, and this work is continuing to give an early idea of aging of the Hysol EA9394 epoxy. Epoxies with similar glass transition temperatures are expected to have similar aging characteristics in terms of bond strength.

Test samples are now being prepared for magnet bond strength testing to be done at both GRC and Cincinnati Testing Laboratories of Cincinnati, OH. Testing will include both static bond strength and fatigue testing. Short-term accelerated aging tests will also be completed by GRC. Radiation effects are initially being evaluated through a literature study. Radiation exposure testing will be done in the future in conjunction with the Fission Surface Power project, which is evaluating higher-power Stirling convertors for lunar and Mars surface applications.

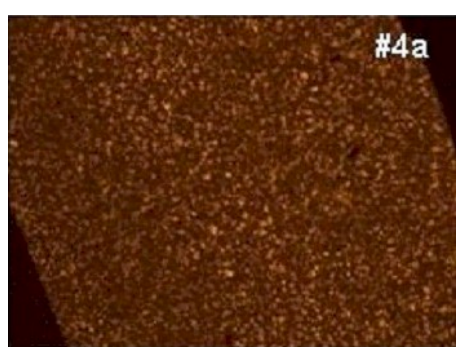

(a) Epoxy sample from thinky mixer.

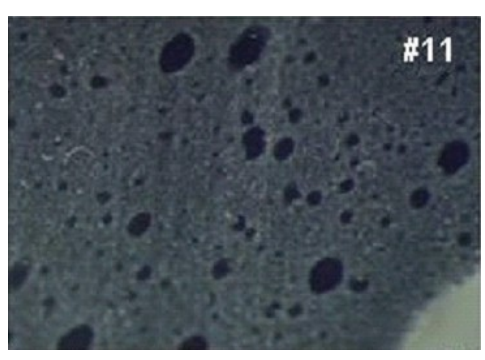

(b) Epoxy sample from hand mixing.

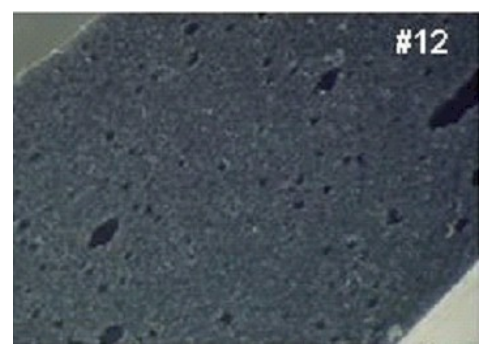

(c) Epoxy sample from hand mixing.

Figure 7.-Epoxy samples from optimized process with thinky mixer compared to hand mixing. 


\section{Magnets and Linear Alternators}

Long-life testing of candidate magnet samples continues. Techniques for characterizing and testing for potential aging effects have been reported by Geng, Niedra, and Schwarze (2005). Tests were performed on 1-cm cube samples to characterize the performed of the magnet material selected for the ASC-E. The magnets are high performance neodymium-iron-boron $(\mathrm{NdFeB})$ magnets that provide margin under all operating conditions. The remanence, intrinsic coercivity and magnetization were measured for each of the samples over the temperature range of 20 to $140^{\circ} \mathrm{C}$. These tests are used to verify the performance of the magnet material against vendor specifications and to check for consistency of the characteristics.

Following characterization, the selected magnet grade underwent a 200-hour, short-term aging test, with the samples exposed to a field of $-5.0 \mathrm{kOe}$ and at $150{ }^{\circ} \mathrm{C}$. These conditions exceed the expected operating conditions of the convertor and were chosen to accentuate any possible aging effects. Magnet grades need to demonstrate minimal to no change in properties during the short-term test and are then candidates for a long-term aging test. The long-term test is exposing the magnets to a $-9.0 \mathrm{kOe}$ demagnetizing field at $130{ }^{\circ} \mathrm{C}$ in a helium environment. This condition is in excess of what would be expected in the ASRG system to demonstrate margin. The long-term aging test is planned for 18,000 hr. As of October 2007, approximately 7,000 hr of the test have been completed.

In anticipation of potential higher-temperature operation, as would exist at some locations on the lunar surface, a long-term magnet aging test of five Samarium-Cobalt ( $\mathrm{SmCo}$ ) magnet samples from two different vendors has been initiated on a second test rig. In this test, the magnets are maintained at a temperature of $250{ }^{\circ} \mathrm{C}$ in a helium environment while being exposed to a constant external demagnetization field of $-9 \mathrm{kOe}$. The magnets have now been under test for over 2,000 hr of the planned 18,000-hr duration.

\section{Reliability}

All of the aforementioned efforts were created to mitigate risk and address reliability for the long-life application. Stirling convertors of this general type, based on non-contacting operation and the elimination of wear mechanisms by design, prove challenging when establishing life and reliability. While components can be tested at accelerated conditions, the full operating Stirling convertor cannot. Because of this, the GRC reliability effort has been formulated to be multi-faceted. It makes use of classic techniques such as failure modes, effects, and criticality analysis (FMECA); reliability block diagrams; and fault tree analyses. It also includes probabilistic techniques that are applied to many of the key components such as the heater head. Extended operation of convertors provides further data regarding potential aging effects. The approach follows a sequence of (1) identifying risks and failure modes, (2) characterizing the failure modes, (3) mitigating the risks associated with each failure mode to a level where (4) the resulting risk can be accepted.

Assessing reliability of the ASC can also rely on experience and data gained from cryocoolers that are used on a variety of spacecraft and ones that are based on the same technology (Ross, 2005). Data from Super Conductor Technology (O'Baid, 2004) and from the company web site indicates more than $120,000,000 \mathrm{hr}$ of operation with over 5,000 units in the field, and a demonstrated mean time between failure of greater than $1,000,000 \mathrm{hr}$ for a cryocooler based on much of the same technology as the ASC. This technology has also been used in space on the RHESSI mission. The cryocooler on RHESSI has operated continuously since February of 2002 and has accumulated over 50,000 hr in space, in addition to the greater than $16,000 \mathrm{hr}$ of operation prior to launch.

\section{Summary}

NASA GRC continues to support the transition of Stirling power conversion technology as it progresses towards flight development. Tasks at GRC have transitioned from supporting the TDC-based 
SRG110 generator to the ASC-based ASRG generator. The tasks have the overall goal of mitigating risk and enhancing reliability for the long-life application. Project highlights of the redirected effort were described in this report and include over $15,000 \mathrm{hr}$ of accumulated extended operating testing of ASC convertors in air and in thermal vacuum environment, heater head life assessment, including structural benchmark testing, and magnet aging characterization on neodymium-iron-boron permanent magnets. Numerous materials-related efforts were also described in the areas of metallics and organics.

\section{References}

1. Bowman, R. and Ritzert, F., and Freedman, M., Evaluation of Candidate Materials for a HighTemperature Stirling Convertor Heater Head, NASA/TM-2003-212734, NASA Glenn Research Center, Cleveland, OH, 2003.

2. Chan, J., Wood, J.G., and Schreiber, J.G., "Development of Advanced Stirling Radioisotope Generator for Space Exploration," in the proceedings of Space Technology and Applications International Forum (STAIF-2007), edited by M.S. El-Genk, AIP Conference Proceedings, Melville, NY, 2007.

3. Cockfield, R.D. and Chan, T.S., "Stirling Radioisotope Generator for Mars Surface and Deep Space Missions," in the proceedings of 37th Intersociety Energy Conversion Engineering Conference, Institute of Electrical and Electronic Engineers, Washington, D.C., 2002, paper no. 20188.

4. Geng, S.M., Schwarze, G.E., and Niedra, J.M., Overview of NASA Magnet and Linear Alternator Research Efforts, NASA/TM-2005-213411, NASA Glenn Research Center, Cleveland, OH, 2005.

5. Krause, D.L., Kalluri, S., and Bowman, R.R., "Structural Benchmark Testing for Stirling Convertor Heater Heads," in the proceedings of Space Technology and Applications International Forum (STAIF-2007), edited by M.S. El-Genk, AIP Conference Proceedings 880, Melville, NY, 2007.

6. O'Baid, A., Fiedler, A., and Karandikar, A., "STI's Solution for High Quantity Production of Stirling Coolers," in Proceedings of Cryocoolers 13, New Orleans, LA, 2004.

7. Oriti, S.M., Update on Extended Operation of Stirling Convertors in Thermal Vacuum at NASA Glenn Research Center, NASA/TM-2006-214424, NASA Glenn Research Center, Cleveland, OH, 2006.

8. Ross, R.G., "Aerospace Coolers: a 50-Year Quest for Long-life Cryogenic Cooling in Space," in the Proceedings of the Cryogenic Engineering Conference, Keystone, CO, 2005.

9. Schreiber, J.G., "Developmental Considerations on the Free-Piston Stirling Power Convertor for Use in Space," in the proceedings of 4th International Energy Conversion Engineering Conference, American Institute of Aeronautics and Astronautics, Reston, VA, 2006, AIAA-2006-4015.

10. Schreiber, J.G., and Thieme, L.G., "Final Results for the GRC Supporting Technology Development Project for the 110-Watt Stirling Radioisotope Generator (SRG110)," in the proceedings of Space Technology and Applications International Forum (STAIF-2007), edited by M.S. El-Genk, AIP Conference Proceedings, Melville, NY, 2007.

11. Shaltens, R.K., and Wong, W.A., Advanced Stirling Technology Development at NASA Glenn Research Center, NASA/TM-2007-214930, NASA Glenn Research Center, Cleveland, OH, 2007.

12. Wong, W.A., Anderson, D.J., Tuttle, K., and Tew, R.C., "Status of NASA's Advanced Radioisotope Power Conversion Technology Research and Development," in proceedings of Space Technology and Applications International Forum (STAIF-2006), edited by M. S. El-Genk, American Institute of Physics 813, Melville, New York, 2006, pp. 340-347.

13. Wood, J.G., Wilson, K., Buffalino, A., Wong, W.A., Frye, P., Matejczyk, D., and Penswick, L.B., "Continued Development of the Advanced Stirling Convertor (ASC)," in the proceedings of 5th International Energy Conversion Engineering Conference, published by the American Institute of Aeronautics and Astronautics, Reston, VA, 2007, AIAA-2007-4704. 


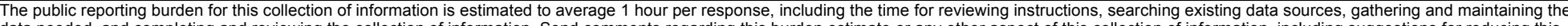

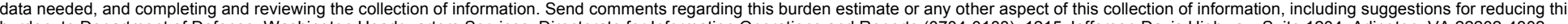

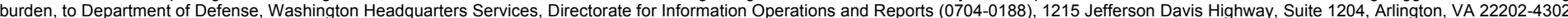

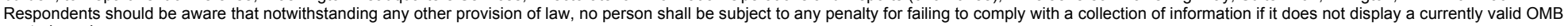
control number.

PLEASE DO NOT RETURN YOUR FORM TO THE ABOVE ADDRESS.

\section{REPORT DATE (DD-MM-YYYY) \\ 2. REPORT TYPE \\ 3. DATES COVERED (From - To)}

01-07-2008

\section{TITLE AND SUBTITLE}

Technical Memorandum

GRC Supporting Technology for NASA's Advanced Stirling Radioisotope Generator (ASRG)

\section{5a. CONTRACT NUMBER}

5b. GRANT NUMBER

5c. PROGRAM ELEMENT NUMBER

\section{AUTHOR(S)}

Schreiber, Jeffrey, G.; Thieme, Lanny, G.

\section{5d. PROJECT NUMBER}

5e. TASK NUMBER

5f. WORK UNIT NUMBER

WBS 138494.04.01.01

8. PERFORMING ORGANIZATION

REPORT NUMBER

E-16467

National Aeronautics and Space Administration

John H. Glenn Research Center at Lewis Field

Cleveland, Ohio 44135-3191

\section{SPONSORING/MONITORING AGENCY NAME(S) AND ADDRESS(ES)}

National Aeronautics and Space Administration

Washington, DC 20546-0001

\section{SPONSORING/MONITORS ACRONYM(S) \\ NASA \\ 11. SPONSORING/MONITORING REPORT NUMBER \\ NASA/TM-2008-215196}

\section{DISTRIBUTION/AVAILABILITY STATEMENT}

Unclassified-Unlimited

Subject Category: 20

Available electronically at http://gltrs.grc.nasa.gov

This publication is available from the NASA Center for AeroSpace Information, 301-621-0390

\section{SUPPLEMENTARY NOTES}

\section{ABSTRACT}

From 1999 to 2006, the NASA Glenn Research Center (GRC) supported a NASA project to develop a high-efficiency, nominal 110-We Stirling Radioisotope Generator (SRG110) for potential use on NASA missions. Lockheed Martin was selected as the System Integration Contractor for the SRG110, under contract to the Department of Energy (DOE). The potential applications included deep space missions, and Mars rovers. The project was redirected in 2006 to make use of the Advanced Stirling Convertor (ASC) that was being developed by Sunpower, Inc. under contract to GRC, which would reduce the mass of the generator and increase the power output. This change would approximately double the specific power and result in the Advanced Stirling Radioisotope Generator (ASRG). The SRG110 supporting technology effort at GRC was replanned to support the integration of the Sunpower convertor and the ASRG. This paper describes the ASRG supporting technology effort at GRC and provides details of the contributions in some of the key areas. The GRC tasks include convertor extended-operation testing in air and in thermal vacuum environments, heater head life assessment, materials studies, permanent magnet characterization and aging tests, structural dynamics testing, electromagnetic interference and electromagnetic compatibility characterization, evaluation of organic materials, reliability studies, and analysis to support controller development.

\section{SUBJECT TERMS}

Stirling; Radioisotope; Space power; Reliability; Organics; Magnets; EMI/EMC; Structural dynamics

\begin{tabular}{|c|c|c|c|c|}
\hline \multicolumn{3}{|c|}{ 16. SECURITY CLASSIFICATION OF: } & \multirow{2}{*}{$\begin{array}{l}\text { 17. LIMITATION OF } \\
\text { ABSTRACT } \\
\text { UU }\end{array}$} & \multirow{2}{*}{$\begin{array}{l}\text { 18. NUMBER } \\
\text { OF } \\
\text { PAGES } \\
18\end{array}$} \\
\hline $\begin{array}{l}\text { a. REPORT } \\
\mathrm{U}\end{array}$ & $\begin{array}{l}\text { b. ABSTRACT } \\
U\end{array}$ & $\begin{array}{l}\text { c. THIS } \\
\text { PAGE } \\
\text { U }\end{array}$ & & \\
\hline
\end{tabular}

19a. NAME OF RESPONSIBLE PERSON
STI Help Desk (email:help@sti.nasa.gov)
19b. TELEPHONE NUMBER (include area code)
301-621-0390



